\title{
Impact of Regional Nodal Irradiation for Breast Cancer Patients with Supraclavicular and/or Internal Mammary Lymph Node Involvement: A Multicenter, Retrospective Study (KROG 16-14)
}

\author{
Kyubo Kim, MD, PhD \\ Yuri Jeong, MD2 \\ Kyung Hwan Shin, MD, $\mathrm{PhD}^{3}$ \\ Jin Ho Kim, MD, PhD ${ }^{3}$ \\ Seung Do Ahn, MD, PhD \\ Su Ssan Kim, MD, PhD ${ }^{4}$ \\ Chang-Ok Suh, MD, PhD \\ Yong Bae Kim, MD, PhD \\ Doo Ho Choi, MD, PhD 6 \\ Won Park, MD, PhD ${ }^{6}$ \\ Jihye Cha, $\mathrm{MD}, \mathrm{PhD}^{7}$ \\ Mison Chun, MD, PhD \\ Dong Soo Lee, MD ${ }^{9}$ \\ Sun Young Lee, MD, PhD ${ }^{10}$ \\ Jin Hee Kim, MD, PhD ${ }^{11}$ \\ Hae Jin Park, MD, PhD ${ }^{12}$ \\ Wonguen Jung, MD, $\mathrm{PhD}^{1}$
}

*A list of author's affiliations appears at the end of the paper.

Correspondence: Kyung Hwan Shin, MD, PhD Department of Radiation Oncology,

Seoul National University College of Medicine, 101 Daehak-ro, Jongno-gu, Seoul 03080, Korea Tel: 82-2-2072-2524

Fax: 82-2-765-3317

E-mail: radiat@snu.ac.kr

Co-correspondence: Su Ssan Kim, MD, PhD Department of Radiation Oncology,

Asan Medical Center, University of Ulsan College of Medicine, 88 Olympic-ro 43-gil,

Songpa-gu, Seoul 05505, Korea

Tel: 82-2-3010-5680

Fax: 82-2-3010-6950

E-mail: watermountain@hanmail.net

Received October 20, 2018

Accepted March 13, 2019

Published Online March 15, 2019

${ }^{*}$ Kyubo Kim and Yuri Jeong contributed equally to this work.

\section{Purpose}

The purpose of this study was to evaluate the treatment outcomes of radiotherapy (RT) for breast cancer with ipsilateral supraclavicular (SCL) and/or internal mammary (IMN) lymph node involvement.

\section{Materials and Methods}

A total of 353 patients from 11 institutions were included. One hundred and thirty-six patients had SCL involvement, 148 had IMN involvement, and 69 had both. All patients received neoadjuvant systemic therapy followed by breast-conserving surgery or mastectomy, and postoperative RT to whole breast/chest wall. As for regional lymph node irradiation, SCL RT was given to 344 patients, and IMN RT to 236 patients. The median RT dose was 50.4 Gy.

\section{Results}

The median follow-up duration was 61 months (range, 7 to 173 months). In-field progression was present in SCL $(n=20)$ and/or IMN $(n=7)$. The 5-year disease-free survival (DFS) and overall survival rates were $57.8 \%$ and $75.1 \%$, respectively. On multivariate analysis, both $\mathrm{SCL} / \mathrm{IMN}$ involvement, number of axillary lymph node $\geq 4$, triple-negative subtype, and mastectomy were significant adverse prognosticators for DFS $(p=0.022, p=0.001, p=0.001$, and $p=0.004$, respectively). Regarding the impact of regional nodal irradiation, SCL RT dose $\geq 54$ Gy was not associated with DFS (5-year rate, 52.9\% vs. 50.9\%; $p=0.696$ ) in SCLinvolved patients, and the receipt of IMN RT was not associated with DFS (5-year rate, $56.1 \%$ vs. 78.1\%; $p=0.099$ ) in IMN-involved patients.

\section{Conclusion}

Neoadjuvant chemotherapy followed by surgery and postoperative RT achieved an acceptable in-field regional control rate in patients with SCL and/or IMN involvement. However, a higher RT dose to SCL or IMN RT was not associated with the improved DFS in these patients. 


\section{Introduction}

Since the recent publication of randomized controlled trials $[1,2]$, elective regional nodal radiotherapy (RT) including supraclavicular lymph nodes (SCL) and internal mammary lymph nodes (IMN) has become the standard treatment in the adjuvant RT for node-positive breast cancer. In the meanwhile, neoadjuvant systemic therapy (NST) followed by surgery and postoperative RT is a widely accepted treatment for breast cancer with clinically apparent SCL or IMN [3-5]. Initially involved nodal areas are usually included in the RT field, but there are little data on the impact of regional nodal $\mathrm{RT}$ in this setting.

Historically, SCL involvement presented as palpable disease, and the IMN involvement was confirmed after surgical excision such as extended radical mastectomy. With the development of imaging technologies such as positron emission tomography-computed tomography (PET-CT), however, extra-axillary regional lymph nodes in locally advanced breast cancer have been increasingly detected [6-8]. Despite the possibility of over-diagnosis, non-palpable SCL and / or clinically detected IMN involvement is becoming more and more common, and more data on the treatment outcome in this setting is needed.

In this study, we evaluated the treatment outcomes of NST followed by surgery and postoperative RT for breast cancer with SCL and/or IMN involvement and investigated the impact of regional nodal RT on the outcomes in these patients.

\section{Materials and Methods}

\section{Study population}

After institutional review board approval, a total of 353 patients with involved SCL and / or IMN but without distant metastases were included from 11 institutions between January 2000 and December 2013. SCL and / or IMN metastases were defined as involvement on imaging studies including PET-CT, magnetic resonance imaging (MRI) of the breast, chest $\mathrm{CT}$, and / or breast ultrasonography (US).

Overall, PET-CT was performed in 325 patients $(92.1 \%)$, MRI in 274 (77.6\%), CT in 119 (33.7\%), and US in 342 (96.9\%). Among patients with SCL involvement $(\mathrm{n}=205)$, SCL was observed in PET-CT (173 of 189), MRI (71 of 141), CT (41 of 76), and US (146 of 198). Meanwhile, IMN was observed in PET-CT (184 of 205), MRI (134 of 187), CT (37 of 69), and US (127 of 213) among 217 patients with IMN involvement.
According to the number of imaging modalities, all four modalities identified SCL in three patients, three modalities in 71 , two modalities in 75 , and a single modality in 56 , while IMN was identified by all four modalities in three patients, three modalities in 95, two modalities in 67 , and a single modality in 52. Pathological confirmation was done in 99 patients for SCL and 59 patients for IMN.

\section{Treatment}

All patients received NST. Chemotherapeutic regimen was adriamycin-based chemotherapy $(n=60)$, taxane-based chemotherapy $(n=268)$, and others $(n=18)$. Seven patients received hormonal therapy and / or anti-human epidermal growth factor receptor 2 (HER2) therapy without cytotoxic chemotherapy.

With regard to surgical treatment for breast, mastectomy was performed in 224 patients, breast-conserving surgery in 127 , and no breast surgery in two due to occult breast cancer. Axillary lymph node dissection was performed in 304 patients and sentinel lymph node biopsy in 49 . Fifty-nine patients underwent SCL excision and 14 patients underwent IMN excision.

Postoperative RT was given to breast/chest wall up to a median dose of $50.4 \mathrm{~Gy}$ (range, 43.2 to $70 \mathrm{~Gy}$ ). SCL RT was given in 344 patients, and IMN RT in 236. The median dose to SCL and IMN was $50.4 \mathrm{~Gy}$ (range, 45 to $70.4 \mathrm{~Gy}$ ) and 50.4 Gy (range, 43.2 to $66 \mathrm{~Gy}$ ), respectively.

One hundred and fifty patients received adjuvant chemotherapy: adriamycin-based chemotherapy in 22 patients, taxane-based chemotherapy in 100, and others in 28 . One hundred and ninety-one patients received hormonal therapy, and 111 patients received anti-HER2 therapy.

\section{Statistical analysis}

Local recurrences were defined as disease recurrences in the ipsilateral breast or chest wall, and regional recurrences as those in the ipsilateral axillary lymph node, SCL, and/or IMN. Disease recurrences other than local and/or regional recurrences were defined as distant metastases. The time between initial treatment and recurrence or last follow-up was measured as disease-free survival (DFS). Overall survival (OS) was defined from the date of initial treatment to the date of death from any cause or last follow-up. The actuarial survival rates were calculated by the Kaplan-Meier method and compared using the log-rank test. On multivariate analysis, Cox proportional-hazards model was applied. Factors with p-value $<0.05$ on univariate analysis were included in the multivariate analysis. A $p<0.05$ was considered statistically significant. Differences in categorical variables were compared using the standard chi-square test or 
Table 1. Patient and tumor characteristics

\begin{tabular}{|c|c|}
\hline Variable & No. $(\%)(\mathrm{n}=353)$ \\
\hline Age (yr) & $47(23-84)$ \\
\hline \multicolumn{2}{|l|}{ Clinical T category } \\
\hline cT1-2 & $188(53.3)$ \\
\hline cT3-4 & $161(45.6)$ \\
\hline cTx & $4(1.1)$ \\
\hline \multicolumn{2}{|l|}{ Nodal involvement } \\
\hline IMN only & $148(41.9)$ \\
\hline SCL only & $136(38.5)$ \\
\hline SCL+IMN & $69(19.5)$ \\
\hline \multicolumn{2}{|c|}{ Pathologic T category } \\
\hline урТ0 & $47(13.3)$ \\
\hline ypTis & $19(5.4)$ \\
\hline ypT1 & $129(36.5)$ \\
\hline урТ2 & $87(24.6)$ \\
\hline урТ3-4 & $71(20.1)$ \\
\hline \multicolumn{2}{|c|}{ No. of positive axillary nodes } \\
\hline 0 & $103(29.2)$ \\
\hline $1-3$ & $98(27.8)$ \\
\hline $4-9$ & $90(25.5)$ \\
\hline$\geq 10$ & $62(17.6)$ \\
\hline \multicolumn{2}{|c|}{ Hormonal receptor status } \\
\hline Positive & $187(53.0)$ \\
\hline Negative & $166(47.0)$ \\
\hline \multicolumn{2}{|l|}{ HER2 status } \\
\hline Positive & $132(37.4)$ \\
\hline Negative & $207(58.6)$ \\
\hline Equivocal & $14(4.0)$ \\
\hline \multicolumn{2}{|c|}{ SCL response to NST } \\
\hline Clinical CR & $267(75.6)$ \\
\hline Clinical non-CR & $72(20.4)$ \\
\hline Unknown & $14(4.0)$ \\
\hline \multicolumn{2}{|c|}{ IMN response to NST } \\
\hline Clinical CR & $268(75.9)$ \\
\hline Clinical non-CR & 66 (18.7) \\
\hline Unknown & $19(5.4)$ \\
\hline
\end{tabular}

Values are presented as median (range) or number (\%). IMN, internal mammary lymph node; SCL, supraclavicular lymph node; HER2, human epidermal growth factor receptor 2; NST, neoadjuvant systemic therapy; CR, complete remission.

Fisher exact test. All statistical analyses were performed using SPSS software (release 18.0.1. SPSS Inc., Chicago, IL).

\section{Ethical statement}

The institutional review board approved this study (approval number: H-1612-095-815 at Seoul National University

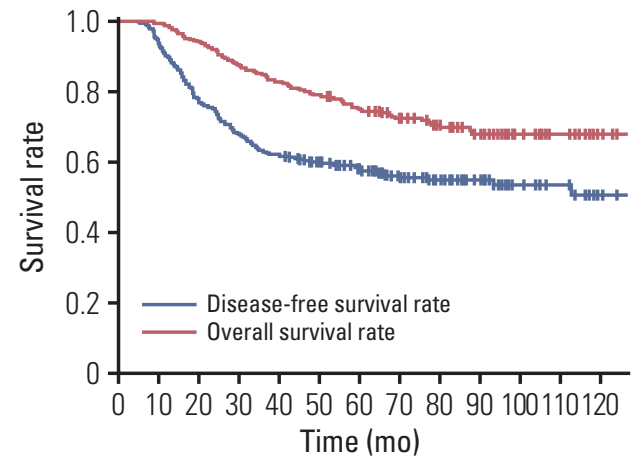

Fig. 1. Disease-free and overall survival curves among all the patients $(\mathrm{n}=353)$.

Hospital), and waived the requirement for obtaining informed consent.

\section{Results}

\section{Characteristics}

The patient and tumor characteristics are summarized in Table 1 . The median age was 47 years (range, 23 to 84 years). As for clinical T category, 188 patients had cT1-2, and 161 had cT3-4 disease. One hundred and thirty-six patients had SCL involvement, 148 had IMN involvement, and 69 had both. After NST, pathologic T categories were as follows: ypT0-is in 66 patients, ypT1-2 in 216, and ypT3-4 in 71. The number of involved axillary lymph nodes was 0 in 103 patients, 1-3 in 98, 4-9 in 90, and $\geq 10$ in 62 . Regarding the response of SCL and IMN to NST, each $75.9 \%$ of patients showed clinical complete remission (CR) on imaging. Hormonal receptor was positive in $53.0 \%$ of patients, and HER2 positivity was observed in $37.4 \%$ of patients.

\section{Outcomes and prognostic factors}

The median duration of follow-up was 61 months (range, 7 to 173 months). There were 67 patients with loco-regional recurrences and 140 patients with distant metastases. Among loco-regional recurrences, 20 patients had isolated local recurrences, 23 isolated regional recurrences, and 24 local and regional recurrences. The 5-year DFS and OS were 57.8\% and $75.1 \%$, respectively (Fig. 1).

On univariate analysis, ypT category, extent of SCL and / or IMN involvement, number of involved axillary lymph nodes, histologic grade, lymphovascular invasion, molecular 
Table 2. Univariate and multivariate analyses for DFS and OS

\begin{tabular}{|c|c|c|c|c|c|c|c|c|}
\hline \multirow[b]{2}{*}{ Variable } & \multicolumn{4}{|c|}{ DFS } & \multicolumn{4}{|c|}{ OS } \\
\hline & $\begin{array}{l}\text { 5-Year } \\
\text { rate }\end{array}$ & $\begin{array}{c}\text { p-value } \\
\text { (univariate }\end{array}$ & $\begin{array}{c}\mathrm{HR} \\
(95 \% \mathrm{CI}) \quad \text { (m }\end{array}$ & $\begin{array}{c}\text { p-value } \\
\text { (multivariate) }\end{array}$ & $\begin{array}{l}\text { 5-Year } \\
\text { rate }\end{array}$ & $\begin{array}{c}\text { p-value } \\
\text { (univariate) }\end{array}$ & $\begin{array}{c}\text { HR } \\
(95 \% \mathrm{CI})\end{array}$ & $\begin{array}{c}\text { p-value } \\
\text { multivariate) }\end{array}$ \\
\hline \multicolumn{9}{|l|}{ Age (yr) } \\
\hline$<40$ & 50.9 & 0.089 & & & 74.7 & 0.290 & & \\
\hline$\geq 40$ & 60.3 & & & & 75.3 & & & \\
\hline \multicolumn{9}{|l|}{ ypT category } \\
\hline $0-1$ & 64.1 & 0.002 & 1 & 0.543 & 80.1 & 0.004 & 1 & 0.065 \\
\hline $2-4$ & 50.0 & & $1.126(0.768-1.652)$ & & 68.9 & & $1.534(0.974-2.414)$ & \\
\hline \multicolumn{9}{|c|}{ Nodal involvement } \\
\hline Both SCL/IMN & 47.8 & 0.046 & $1.568(1.066-2.304)$ & ) $\quad 0.022$ & 63.4 & 0.019 & $1.818(1.145-2.887)$ & 0.011 \\
\hline Others & 60.3 & & 1 & & 78.0 & & 1 & \\
\hline \multicolumn{9}{|l|}{$\begin{array}{l}\text { No. of axillary } \\
\text { lymph nodes }\end{array}$} \\
\hline $0-3$ & 72.1 & $<0.001$ & 1 & 0.001 & 80.5 & 0.001 & 1 & 0.354 \\
\hline$\geq 4$ & 49.1 & & $1.950(1.323-2.875)$ & & 68.0 & & $1.235(0.791-1.928)$ & \\
\hline \multicolumn{9}{|l|}{ Histologic grade } \\
\hline 1 or 2 & 61.8 & 0.007 & 1 & 0.081 & 81.4 & 0.001 & 1 & 0.025 \\
\hline 3 & 50.0 & & $1.362(0.963-1.928)$ & & 64.8 & & $1.647(1.065-2.548)$ & \\
\hline \multicolumn{9}{|c|}{ Lymphovascular invasion } \\
\hline Absent & 64.0 & $<0.001$ & 1 & 0.108 & 73.7 & 0.570 & & \\
\hline Present & 49.1 & & $1.363(0.934-1.989)$ & & 76.5 & & & \\
\hline \multicolumn{9}{|l|}{ Molecular subtype } \\
\hline Triple-negative & 39.0 & $<0.001$ & $2.626(1.482-4.653)$ & 3) 0.001 & 58.6 & $<0.001$ & $3.311(2.121-5.170)$ & ) $<0.001$ \\
\hline Others & 63.9 & & 1 & & 80.8 & & 1 & \\
\hline \multicolumn{9}{|l|}{ Breast surgery } \\
\hline BCS & 71.7 & $<0.001$ & 1 & 0.004 & 85.4 & 0.001 & 1 & 0.002 \\
\hline Mastectomy & 49.8 & & $1.911(1.224-2.984)$ & & 69.2 & & $2.421(1.393-4.207)$ & \\
\hline \multicolumn{9}{|l|}{$\begin{array}{l}\text { Postoperative } \\
\text { chemotherapy }\end{array}$} \\
\hline No & 57.6 & 0.802 & & & 73.7 & 0.189 & & \\
\hline Yes & 57.7 & & & & 77.0 & & & \\
\hline \multicolumn{9}{|l|}{ Hormonal therapy } \\
\hline No & 49.2 & $<0.001$ & 1 & 0.620 & 65.8 & $<0.001$ & 1 & 0.350 \\
\hline Yes & 65.1 & & $0.884(0.542-1.441)$ & & 83.0 & & $0.760(0.427-1.352)$ & \\
\hline \multicolumn{9}{|l|}{ Herceptin } \\
\hline No & 54.2 & 0.042 & 1 & 0.867 & 72.3 & 0.032 & 1 & 0.270 \\
\hline Yes & 65.5 & & $0.960(0.595-1.549)$ & & 81.0 & & $0.687(0.352-1.338)$ & \\
\hline
\end{tabular}

DFS, disease-free survival; OS, overall survival; HR, hazard ratio; CI, confidence interval; SCL, supraclavicular lymph node;

IMN, internal mammary lymph node; BCS, breast-conserving surgery.

subtype, type of breast surgery, hormonal therapy, and antiHER2 therapy were significantly associated with DFS. On multivariate analysis, both SCL and IMN involvement (hazard ratio [HR], 1.568; 95\% confidence interval [CI], 1.066 to 2.304; $\mathrm{p}=0.022$ ), four or more involved axillary lymph nodes (HR, 1.950; 95\% CI, 1.323 to 2.875; $\mathrm{p}=0.001$ ), triple-negative subtype (HR, 2.626; 95\% CI, 1.482 to 4.653; $\mathrm{p}=0.001$ ), and mastectomy (HR, 1.911; 95\% CI, 1.224 to $2.984 ; \mathrm{p}=0.004)$ were adverse prognostic factors for DFS (Table 2).

With regard to OS, ypT cateogry, extent of SCL and/or IMN involvement, number of involved axillary lymph nodes, histologic grade, molecular subtype, type of breast surgery, hormonal therapy, and anti-HER2 therapy were significant prognostic factors on univariate analysis. Among these, both SCL and IMN involvement (HR, 1.818; 95\% CI, 1.145 to 2.887; $\mathrm{p}=0.011$ ), histologic grade 3 (HR, 1.647; 95\% 
Table 3. Patterns of SCL failure among 201 SCL-involved patients receiving SCL RT

\begin{tabular}{|c|c|c|c|c|}
\hline & \multicolumn{2}{|c|}{ Recurrence in SCL/Total } & \multirow{2}{*}{ Total } & \multirow{2}{*}{ p-value } \\
\hline & SCL RT $\geq 54$ Gy & SCL RT < 54 Gy & & \\
\hline CR to NSTa) & $3 / 45(6.7)$ & 6/70 (8.6) & $9 / 115(7.8)$ & $>0.990$ \\
\hline Non-CR to NST $\left.{ }^{a}\right)$ & $7 / 28(25.0)$ & $1 / 44(2.3)$ & $8 / 72(11.1)$ & 0.005 \\
\hline CR to $\mathrm{NST}^{\mathrm{b})}$ & $3 / 41(7.3)$ & $6 / 62(9.7)$ & $9 / 103(8.7)$ & $>0.990$ \\
\hline Non-CR to NST $\left.{ }^{b}\right)$ & $3 / 14(21.4)$ & $0 / 11(0)$ & $3 / 25(12.0)$ & 0.230 \\
\hline Total & $11 / 79(13.9)$ & $9 / 122(7.4)$ & $20 / 201(10.0)$ & 0.130 \\
\hline
\end{tabular}

Values are presented as number (\%). SCL, supraclavicular lymph node; RT, radiotherapy; CR, complete remission; NST, neoadjuvant systemic therapy. a) 14 patients, whose response to NST was unavailable, were excluded, ${ }^{\text {b) }} 73$ patients, whose response to NST was unavailable and who underwent SCL excision, were excluded.

Table 4. Patterns of IMN failure among 217 IMN-involved patients

\begin{tabular}{lccrr} 
& \multicolumn{2}{c}{ Recurrence in IMN/Total } & Total & p-value \\
\cline { 2 - 3 } & \multicolumn{1}{c}{ IMN RT (+) } & IMN RT (-) & & \\
CR to NST & $3 / 109(2.8)$ & $3 / 23(13.0)$ & $6 / 132(4.5)$ & 0.065 \\
Non-CR to NST $^{\text {a) }}$ & $4 / 60(6.7)$ & $0 / 6(0)$ & $4 / 66(6.1)$ & $>0.990$ \\
CR to NST $^{\text {b) }}$ & $3 / 107(2.8)$ & $3 / 23(13.0)$ & $6 / 130(4.6)$ & 0.068 \\
Non-CR to NST $^{\text {b) }}$ & $4 / 48(8.3)$ & $0 / 6(0)$ & $4 / 54(7.4)$ & $>0.990$ \\
Total & $7 / 185(3.8)$ & $3 / 32(9.4)$ & $10 / 217(4.6)$ & 0.169 \\
\hline
\end{tabular}

Values are presented as number (\%). IMN, internal mammary lymph node; RT, radiotherapy; CR, complete remission; NST, neoadjuvant systemic therapy. ${ }^{a)} 19$ patients, whose response to NST was unavailable, were excluded, ${ }^{b} 33$ patients, whose response to NST was unavailable and who underwent IMN excision, were excluded.

$\mathrm{CI}, 1.065$ to $2.548 ; \mathrm{p}=0.025)$, triple-negative subtype (HR, 3.311; 95\% CI, 2.121 to 5.170; $<$ 0.001), and mastectomy (HR, 2.421; $95 \%$ CI, 1.393 to $4.207 ; \mathrm{p}=0.002$ ) were independently correlated with a worse OS on multivariate analysis (Table 2).

\section{Patterns of SCL and IMN failure according to the treat- ments}

Among 205 patients with SCL involvement, 201 patients received SCL RT. More patients failed in the SCL with the higher RT dose to SCL $\geq 54 \mathrm{~Gy}$, but the difference was not statistically significant $(13.9 \%$ vs. $7.4 \%, \mathrm{p}=0.130)$. According to the response of SCL to NST, significantly more SCL failures were observed with $\geq 54 \mathrm{~Gy}$ in patients failing to achieve CR to NST $(25.0 \%$ vs. $2.3 \%, \mathrm{p}=0.005)$. When 59 patients undergoing SCL excision were excluded, there were no differences in the crude SCL failure rates according to the dose to the SCL (Table 3). Among those patients who underwent SCL excision, 12 patients achieved CR to NST and 47 did not, and five patients who failed to achieve CR experienced SCL failures. Regarding four patients who did not receive SCL
RT, they achieved CR to NST and did not undergo SCL excision, and there were no SCL failures during follow-up.

One hundred and eighty-five of 217 patients with IMN involvement received IMN RT. As for IMN failure, there was no significant difference according to the receipt of IMN RT in patients with IMN involvement (3.8\% vs. 9.4\%, $\mathrm{p}=0.139$ ). Patients achieving CR to NST had more IMN failures when IMN RT was not given, but the difference did not reach a statistical significance $(13.0 \%$ vs. $2.8 \%, \mathrm{p}=0.065)$. When 14 patients undergoing IMN excision were excluded, a similar finding was observed (Table 4). Among those patients who underwent IMN excision, two patients achieved CR to NST and 12 did not, and no patient experienced IMN failure. When a log-rank test was performed in 184 patients who did not undergo IMN excision and whose response to NST was available, the 5-year IMN failure-free survival rates were 96.9\% and $90.9 \%$ in patients with and without IMN RT, respectively ( $\mathrm{p}=0.064$ ) (Fig. 2). 


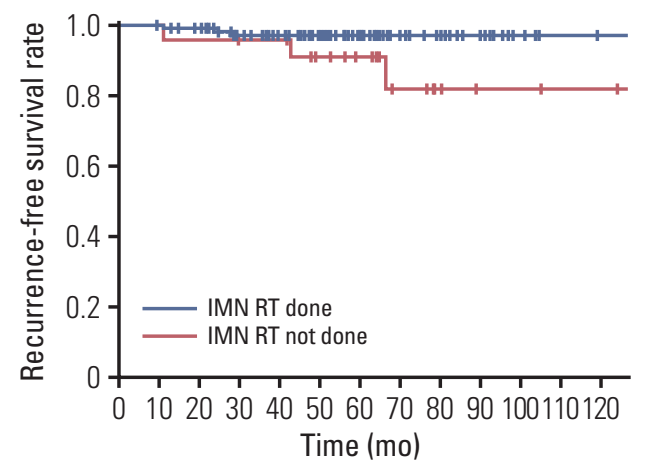

Fig. 2. Internal mammary lymph node (IMN) failure-free survival curves in patients with IMN involvement who did not undergo IMN excision and whose response to neoadjuvant systemic therapy was available $(\mathrm{n}=184)$. RT, radiotherapy.

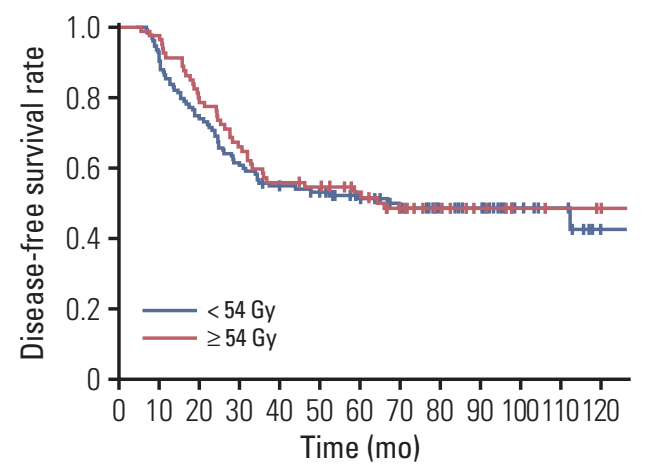

Fig. 3. Disease-free survival curves according to the dose to the supraclavicular lymph node (SCL) among those patients with SCL involvement $(\mathrm{n}=201)$. Four patients not receiving radiation to the SCL were excluded.

\section{Subgroup analysis according to the involvement of SCL or IMN}

Within patients with SCL involvement $(\mathrm{n}=205)$, higher ypT category, four or more involved axillary lymph nodes, histologic grade 3, triple-negative subtype, clinical non-CR of SCL to NST, mastectomy, and SCL excision were associated with an inferior DFS on univariate analysis. However, the SCL RT dose $\geq 54$ Gy did not improve DFS (5-year rate, 52.9\% vs. $50.9 \%$; $\mathrm{p}=0.696$ ) (Fig. 3). On multivariate analysis, four or more involved axillary lymph nodes (HR, 1.636; 95\% CI, 1.020 to $2.621 ; \mathrm{p}=0.041$ ), histologic grade 3 (HR, 1.665; 95\% $\mathrm{CI}, 1.085$ to $2.555 ; \mathrm{p}=0.020$ ), triple-negative subtype (HR, $2.181 ; 95 \% \mathrm{CI}, 1.369$ to $3.473 ; \mathrm{p}=0.001$ ), and mastectomy (HR, $1.867 ; 95 \% \mathrm{CI}, 1.036$ to $3.365 ; \mathrm{p}=0.038$ ) were significant prog-

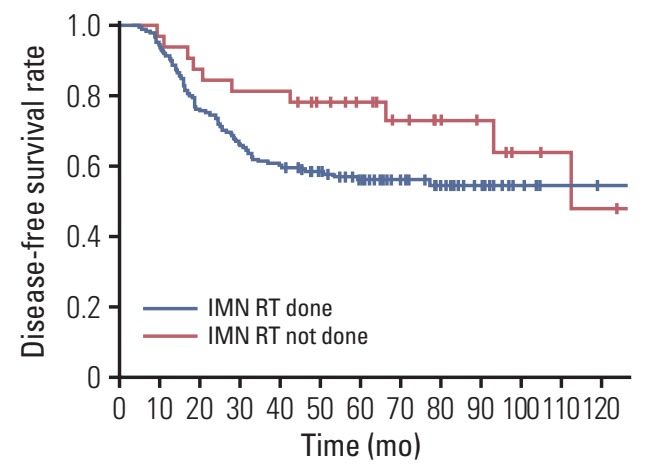

Fig. 4. Disease-free survival curves according to the receipt of internal mammary lymph node (IMN) irradiation among those patients with IMN involvement $(\mathrm{n}=217)$. RT, radiotherapy.

nosticators predicting a worse DFS.

With regard to those patients with IMN involvement $(\mathrm{n}=217)$, additional SCL involvement, four or more involved axillary lymph nodes, lymphovascular invasion, triple-negative subtype, mastectomy, and no hormonal therapy were correlated with an inferior DFS on univariate analysis. However, the receipt of IMN RT did not impact on DFS (5-year rate, $56.1 \%$ with IMN RT vs. $78.1 \%$ without IMN RT; $\mathrm{p}=0.099$ ) (Fig. 4). On multivariate analysis, additional SCL involvement (HR, 1.663; 95\% CI, 1.070 to 2.587; $\mathrm{p}=0.024$ ), four or more involved axillary lymph nodes (HR, 1.814; 95\% CI, 1.098 to 2.998; $\mathrm{p}=0.020$ ), triple-negative subtype (HR, 3.995; $95 \%$ CI, 2.106 to $7.579 ; \mathrm{p}<0.001$ ), and mastectomy (HR, 2.409; $95 \% \mathrm{CI}, 1.405$ to $4.129 ; \mathrm{p}=0.001$ ) were significant adverse prognosticators for DFS.

\section{Impact of SCL or IMN excision on the outcomes}

Among 205 patients with SCL involvement, 59 patients underwent SCL excision along with the breast and axillary surgery. Among these, the response to NST was clinical CR in 12 and non-CR in 47. All of them received SCL RT, and the median dose was 50.4 Gy (range, 45 to 66 Gy). Regarding the patterns of failure, there were 10 patients with local recurrences, nine with regional recurrences including five with SCL recurrences, and 35 with distant metastases. The 5-year DFS was $38.1 \%$, significantly inferior to those without SCL excision $(57.5 \%, \mathrm{p}=0.026)$. As mentioned earlier, however, the significance of SCL excision disappeared on multivariate analysis.

Fourteen of 217 patients with IMN involvement had IMN excision. Among these, the response to NST was clinical CR in two and non-CR in 12. All of them received IMN RT. There were two patients with local recurrences, two with regional 
recurrences (one in axillary lymph node and the other in the SCL), and five with distant metastases. The 5-year DFS was $56.3 \%$, which was not significantly different from those without IMN excision $(59.6 \%, \mathrm{p}=0.901)$.

\section{Discussion}

In our study, the outcomes of NST followed by surgery and postoperative RT were analyzed in 353 breast cancer patients with SCL and/or IMN involvement which was detected on imaging studies. The SCL and/ or IMN failures were rare, and a higher SCL RT dose as well as the receipt of IMN RT was not associated with a better control rate. DFS and OS were comparable with the contemporary results, but were not improved by a higher dose SCL RT and IMN RT.

As for the treatment for extra-axillary regional lymph nodes in breast cancer, especially IMN, there have been a number of historical reports to date [9]. However, extended radical mastectomy has rarely been performed since several randomized trials noted no survival benefit of such an aggressive treatment $[10,11]$. With regard to the management for SCL, some institutions reported the outcomes of SCL excision along with breast surgery, but its benefit is not evident until now [12,13]. Therefore, the involved SCL and/or IMN is usually diagnosed clinically and treated by regional nodal RT combined with systemic therapy.

Recently, especially with the development of imaging studies, more data on the multidisciplinary treatment in this setting are becoming available. Among these, Zhang et al. [5] reviewed 809 patients with cN2-3 patients, and found that 112 patients (13.8\%) had IMN involvement on PET-CT, MRI, CT and/or US [5]. They also analyzed the outcomes of NST followed by surgery and postoperative RT in these patients, and $72.1 \%$ of IMN-involved patients achieved clinical CR on imaging after NST. In the present study, SCL and/or IMN involvement was determined via the same imaging studies, and each $75.9 \%$ of patients with SCL and IMN involvement achieved clinical CR to NST. The treatment outcomes were also very similar, and the 5 -year DFS and OS were $56 \%$ and $76 \%$ in the Zhang et al.'s study [5], and $57.8 \%$ and $75.1 \%$ in our study, respectively. In addition, Noh et al. [14] also reported the treatment outcomes of SCL- and/or IMNinvolved breast cancer which was detected on imaging studies including PET-CT and MRI. When treated with NST followed by surgery and postoperative RT, the 5-year DFS and OS were $60.2 \%$ and $75.5 \%$, respectively. These observations suggest that despite of the advanced nodal disease, favorable DFS and OS can be achieved when multimodality treatments are given. However, these data should be interpreted with caution, because the involvement of SCL and / or IMN might be overestimated on imaging and those patients with occult distant metastases could be excluded after more meticulous imaging studies such as PET-CT compared with historical controls. Compared with aforementioned studies, Huang et al. [4] reported the relatively inferior DFS and OS, that is, $30 \%$ and $47 \%$, respectively, in SCL-involved breast cancer patients receiving multimodality treatments. In this study, SCL involvement was presented as palpable disease in $77.5 \%$ of patients, and clinical CR rate to NST was only $49 \%$. These findings suggest that their population might have a higher tumor burden. In addition, pathologic confirmation of IMN involvement on fine-needle aspiration biopsy was reported to be associated with an inferior progression-free survival compared to those of clinically involved IMN on PET-CT [15].

Regarding the impact of regional nodal RT for SCL and / or IMN, Park et al. [3] analyzed 55 patients with PET-detected $\mathrm{cN} 3$ breast cancer who were treated with NST followed by surgery and postoperative RT. The 5-year locoregional relapse-free survival, DFS, and OS were $80 \%, 60 \%$, and $79 \%$, respectively. And, both the higher RT dose to SCL $\geq 55$ Gy and the receipt of IMN RT was not associated with better outcomes. We also observed similar findings among 353 patients from 11 institutions, that is, DFS was not improved by a higher dose SCL RT or IMN RT. Although the receipt of IMN RT was associated with a lower IMN failure rate even in patients achieving clinical CR to NST, the difference did not reach statistical significance. Rather, more SCL failures were observed with a higher SCL RT dose in patients failing to achieve clinical CR to NST. The paradoxical dose-response relationship could be explained that a higher RT dose might be prescribed to a larger residual lesion after NST. However, the major patterns of failure were distant metastases, and therefore this finding might not be translated into a meaningful DFS difference. In the aforementioned study by Huang et al. [4], a higher SCL RT dose was prescribed to patients with non-CR to NST and was not associated with a better SCL control. However, non-CR to NST was the independent prognostic factor associated with an inferior DFS [4]. Considering the increase of treatment failures in those patients with non-CR to NST (S1 and S2 Tables), more intensified systemic therapy should be incorporated to these patients.

The limitations of this study are as follows. First, there might be potential biases which are the typical shortcomings of retrospective studies. Performance of mastectomy was associated with an inferior DFS, which suggests that patients with more advanced disease underwent mastectomy. Second, the involvement of SCL and/or IMN was determined on imaging studies, and therefore might be overestimated. In some patients undergoing SCL and/or IMN excision or biopsy, the pathologic confirmation was done, but it was not a routine procedure in most institutions. However, the diag- 
nostic accuracy of SCL and / or IMN involvement by PET-CT or US was reported to be about $80 \%-90 \%$ [7,8], and our patients showed positive findings on multiple imaging studies in $72.2 \%$ for SCL involvement and 76.0\% for IMN involvement. Lastly, the extent of SCL and/or IMN involvement was not specified. As mentioned earlier, the paradoxical dose-response relationship between SCL RT dose and SCL failure might be resulted from a higher tumor burden unavailable from the retrospective chart review. Despite these limitations, our study represents one of the largest series on the outcomes of multidisciplinary treatment for breast cancer patients with SCL and /or IMN involvement.

In conclusion, NST followed by surgery and postoperative RT achieved an acceptable in-field regional control rate in patients with SCL and/or IMN involvement. However, a higher SCL RT dose or IMN RT was not associated with the improved DFS in these patients. SCL and/or IMN excision, which was more frequently performed in patients with nonCR to NST, achieved acceptable local control but did not improve DFS, either. Given the major patterns of failure were distant metastases, more intensified systemic therapy should be incorporated especially in those patients with non-CR to NST.

\section{Electronic Supplementary Material}

Supplementary materials are available at Cancer Research and Treatment website (https://www.e-crt.org).

\section{Conflicts of Interest}

Conflict of interest relevant to this article was not reported.

\section{Author Details}

${ }^{1}$ Department of Radiation Oncology, Ewha Womans University College of Medicine, Seoul, ${ }^{2}$ Department of Radiation Oncology, Wonkwang University Hospital, Wonkwang University School of Medicine, Iksan, ${ }^{3}$ Department of Radiation Oncology, Seoul National University College of Medicine, Seoul, ${ }^{4}$ Department of Radiation Oncology, Asan Medical Center, University of Ulsan College of Medicine, Seoul, ${ }^{5}$ Department of Radiation Oncology, Yonsei Cancer Center, Yonsei University College of Medicine, Seoul, ${ }^{\circ}$ Department of Radiation Oncology, Samsung Medical Center, Sungkyunkwan University School of Medicine, Seoul, ${ }^{7}$ Department of Radiation Oncology, Wonju Severance Christian Hospital, Wonju, ${ }^{8}$ Department of Radiation Oncology, Ajou University School of Medicine, Suwon, ${ }^{9}$ Department of Radiation Oncology, Uijeongbu St. Mary's Hospital, College of Medicine, The Catholic University of Korea, Uijeongbu, ${ }^{10}$ Department of Radiation Oncology, Chonbuk National University Hospital, Jeonju, ${ }^{11}$ Department of Radiation Oncology, Keimyung University Dongsan Medical Center, Keimyung University School of Medicine, Daegu, ${ }^{12}$ Department of Radiation Oncology, Hanyang University College of Medicine, Seoul, Korea

\section{References}

1. Poortmans PM, Collette S, Kirkove C, Van Limbergen E, Budach V, Struikmans H, et al. Internal mammary and medial supraclavicular irradiation in breast cancer. N Engl J Med. 2015;373:317-27.

2. Whelan TJ, Olivotto IA, Parulekar WR, Ackerman I, Chua BH, Nabid A, et al. Regional nodal irradiation in early-stage breast cancer. N Engl J Med. 2015;373:307-16.

3. Park HJ, Shin KH, Cho KH, Park IH, Lee KS, Ro J, et al. Outcomes of positron emission tomography-staged clinical N3 breast cancer treated with neoadjuvant chemotherapy, surgery, and radiotherapy. Int J Radiat Oncol Biol Phys. 2011;81: e689-95.

4. Huang EH, Strom EA, Valero V, Fornage B, Perkins GH, Oh $\mathrm{JL}$, et al. Locoregional treatment outcomes for breast cancer patients with ipsilateral supraclavicular metastases at diagnosis. Int J Radiat Oncol Biol Phys. 2007;67:490-6.

5. Zhang YJ, Oh JL, Whitman GJ, Iyengar P, Yu TK, Tereffe W, et al. Clinically apparent internal mammary nodal metastasis in patients with advanced breast cancer: incidence and local control. Int J Radiat Oncol Biol Phys. 2010;77:1113-9.

6. Anderson TL, Glazebrook KN, Murphy BL, Viers LD, Hieken TJ. Cross-sectional imaging to evaluate the extent of regional nodal disease in breast cancer patients undergoing neoadjuvant systemic therapy. Eur J Radiol. 2017;89:163-8.

7. Wang CL, Eissa MJ, Rogers JV, Aravkin AY, Porter BA, Beatty JD. (18)F-FDG PET/CT-positive internal mammary lymph nodes: pathologic correlation by ultrasound-guided fine-needle aspiration and assessment of associated risk factors. AJR Am J Roentgenol. 2013;200:1138-44.

8. Iyengar P, Strom EA, Zhang YJ, Whitman GJ, Smith BD, Woodward WA, et al. The value of ultrasound in detecting extra-axillary regional node involvement in patients with advanced breast cancer. Oncologist. 2012;17:1402-8.

9. Chen RC, Lin NU, Golshan M, Harris JR, Bellon JR. Internal mammary nodes in breast cancer: diagnosis and implications for patient management: a systematic review. J Clin Oncol. 2008;26:4981-9.

10. Lacour J, Le M, Caceres E, Koszarowski T, Veronesi U, Hill C. 
Radical mastectomy versus radical mastectomy plus internal mammary dissection. Ten year results of an international cooperative trial in breast cancer. Cancer. 1983;51:1941-3.

11. Veronesi U, Marubini E, Mariani L, Valagussa P, Zucali R. The dissection of internal mammary nodes does not improve the survival of breast cancer patients. 30-year results of a randomised trial. Eur J Cancer. 1999;35:1320-5.

12. Jung J, Kim SS, Ahn SD, Lee SW, Ahn SH, Son BH, et al. Treatment outcome of breast cancer with pathologically proven synchronous ipsilateral supraclavicular lymph node metastases. J Breast Cancer. 2015;18:167-72.

13. Chang XZ, Yin J, Sun J, Zhang XH, Cao XC. A retrospective study of different local treatments in breast cancer patients with synchronous ipsilateral supraclavicular lymph node metastasis. J Cancer Res Ther. 2013;9 Suppl:S158-61.

14. Noh JM, Kim KH, Park W, Suh CO, Huh SJ, Choi DH, et al. Prognostic significance of nodal involvement region in clinical stage IIIc breast cancer patients who received primary systemic treatment, surgery, and radiotherapy. Breast. 2015;24: 637-41.

15. Joo JH, Kim SS, Ahn SD, Choi EK, Jung JH, Jeong Y, et al. Impact of pathologic diagnosis of internal mammary lymph node metastasis in clinical N2b and N3b breast cancer patients. Breast Cancer Res Treat. 2017;166:511-8. 